\title{
The British Electronics and Computing Industries: Past, Present and Future
}

\author{
Peter S. Excell ${ }^{1, *}$ \\ ${ }^{1}$ Wrexham Glynd $\hat{w} r$ University, Wrexham, United Kingdom \\ p.excell@glyndwr.ac.uk \\ *Correspondence: p.excell@glyndwr.ac.uk
}

Received: $7^{\text {th }}$ April 2018; Accepted: 1st May 2018; Published: 1 ${ }^{\text {st }}$ July 2018

Abstract: A brief review of key milestones in the development of the British Electronics and Computing industries is presented, together with some thoughts about future directions.

Keywords: Electronics industry; British industry; thermionic valves; radio; television; radar; satellite communications; optical fibre; computer industry; mobile communications; electronic entertainment; digital media

\section{Introduction}

Electronics is distinguished from Electrical Engineering by its handling of "light currents", rather than "heavy currents". The commencement of the era of Electronics can arguably be tied to the development of radio (wireless) communications, for which it became essential to work with very weak currents and voltages, whereas not only did power systems use heavy currents but wired telegraph systems could also be arranged to deliver arbitrarily large currents sufficient to drive electro-mechanical relays. Taking this view, one can argue that the very first electronic device was the "coherer", invented by Branly in France [1]: a mysterious device whose functioning is still not really understood. It consists of a tube of metal filings contacting an electrode at each end: a small DC voltage is applied across the electrodes. The conductivity is very poor in its quiescent state, but when it is exposed to a radiofrequency field it becomes conducting and remains so until shaken: this is believed to result from a surface physics effect. This device was followed by improved radio frequency detectors, such as the Marconi magnetic detector [2] and the crystal detector [3]: crystal detectors were essentially solid-state diodes and they continued to be used in the historic form until the mid-20th Century.

A significant development occurred when Marconi (very much mentored by his mother) concluded that the Italian communications organisations were not interested in funding his wireless work and hence he came to Britain at the end of the 19th century and stayed for about four decades, setting up the Marconi company, which was a major player in British telecommunications throughout the 20th century. In 1901 he scored a particular success in demonstrating wireless communications across the Atlantic Ocean even though using relatively crude spark transmitters and passive detectors.

A breakthrough to more recognisable "electronic" devices came with the invention of the thermionic diode by Sir Ambrose Fleming in London, in 1904 [4]. Moving on from this, the really significant step into active devices came with the invention of the triode by Lee de Forest in the USA in 1906 [5], and this was rapidly adopted around the world, including Britain. A company that became a major player in valves (thermionic tubes) was Mullard Ltd, which became a subsidiary of 
the Dutch firm Philips, and every British radio shop would have a valve testing machine made by Mullard. Mullard moved into germanium transistors at quite an early stage, but failed to develop into silicon in a significant way and lost out to competitors, such that the name has now disappeared.

\section{Radio Broadcasting}

A feature of Lee de Forest's career was a large number of battles over patent rights and infringement arguments in the law courts and issues of this type, plus related devious business dealings, also characterised the British electronics industry between the two world wars, when the production of radio sets for consumers became a massive growth industry. In some ways, the fragmentation that this caused was not good for the long-term health of the industry.

A major event which gave great impetus to the development of the radio industry was, ironically, the sinking of the ocean liner "Titanic" in 1912. The liner and most of the other ships around it were fitted with radio transmitters and receivers, but they were not permanently attended and the sinking emphasised the importance of constant monitoring of reliable and modern radio sets on ships. This also became of vital importance in military activities, as illustrated by experience in the First World War soon after. Even at this early stage, eavesdropping on radio signals and on leakage from signals not intended to radiate became a major aspect of intelligence gathering.

In general, the British continued to use spark transmitters for the majority of communications in the First World War, apparently due to lack of a substantial industry manufacturing thermionic valves. It is very noteworthy that a major radio researcher, Edward Appleton, who was employed by the Army to train radio operators and technicians in the First World War, could not acquire a supply of triodes in the UK and hence instead had to acquire captured German ones when he visited the battlefield in France [6]. Appleton later went on to establish the scientific basis of the ionosphere and was awarded the Nobel Prize for Physics for this work.

In the civilian domain, the years between the two world wars saw a great growth in radio broadcasting and hence manufacturing and sales of radio receivers, mostly based on thermionic valves, although there was also a flourishing "homebuilder" culture of creating passive receivers, particularly those known as "crystal sets", which used a non-linear crystal detector as a diode to demodulate AM radio broadcasts [7].

In 1925, Appleton (see above) did the key scientific work that proved the existence of the ionosphere, enabling short wave (HF) radio transmissions around the world [8]. In the area of the British Empire, with significant territories spread from Canada to New Zealand and from Hong Kong to South Africa, this became an additional major source of business.

\section{Television}

In 1926, the Scottish inventor John Logie Baird first demonstrated television, using a rather crude mechanical system [9]. Interest in this developed slowly through the 1930s and it was still very much a luxury for the wealthy when work was halted by the Second World War. However, the technologies involved were of great value in the development of radar and other necessary tools of war. After the war, television began to grow again as a commercial business, and the event that pushed it to become a major desirable purchase for the majority of households was the coronation of Queen Elizabeth II in 1953: sales were huge leading up to this event and television became an established part of the British way of life from then on.

Television manufacturing became a large industry in the United Kingdom for many years, with names such as Bush, Ferguson and Thorn being prominent. However, competition from Japan eventually caused such manufacturing to disappear. An interesting comment on design philosophy that was made at the time was that the later (partially solid-state) British television sets had been made with modular circuit boards that could be removed for testing and maintenance: this is superficially a sound philosophy, but in practice the electronics became so reliable and the manufacturing costs so low that the demand for such maintenance largely disappeared. On the other 
hand, the connectors corroded and caused unreliability: the Japanese sets in general avoided such connectors and hence made massive inroads into the British market.

\section{Microwaves and Radar}

After the end of the Second World War, it became well known that direction finding of enemy radio transmissions and radar, initially for the location of aircraft, were innovations that had been of great use to the military and also had important civilian uses: they were thus given a massive impetus. Britain took the lead in the development of high frequency (X-band) radar, which enabled the transceivers to be installed on aircraft. These could then detect submarine snorkels: critical to the Battle of the Atlantic. In a major trade of secrets with the USA during the War, the British sent a high-level delegation with information on X-band magnetron design in exchange for supply of a complex and advanced American bomb-aiming sight for aircraft (Norden Bombsight) [6].

After the war, radar became an important industry, open to all. In particular, the British company Decca became a major manufacturer of commercial radar equipment, although this has now been absorbed into the global Northrop Grumman group. On the other hand, several of the wartime pioneers changed their research field to radio astronomy, most notably Bernard Lovell, who led construction of the Jodrell Bank radio telescope [10].

\section{Computers}

Even more important during the Second World War, but kept secret until the late 1970s, was the work on code breaking and the development of early computers. Turing's name is well-known in this, but his contribution was in the mathematics of code breaking and the underlying theory of computation. The key electronic hardware development was the construction of the "Colossus" code-breaking computer by Tommy Flowers and associates at the Bletchley Park site [11]. This was surrounded by a very high level of secrecy until the 1970s, but a replica was then constructed, often using just the memories of the people that had worked on it [12]. Because of the secrecy it was difficult for those who had worked on it to exploit their skills after the war, but ways were found and hence several computers of a more general design were constructed in the 1950s. As a result, Britain had quite a thriving computer industry in the mainframe era up to the early 1970s. Unfortunately, financial returns on the products were not good and several mergers were facilitated by the UK Government in the hope that a monopoly producer might be globally competitive. The result was ICL (International Computers Ltd) but its commercial performance was insufficient to overcome (primarily) American competition and eventually it was sold to Fujitsu in the 1970s.

Computers in that era were viewed as specialised tools of science, to be used by highly qualified personnel. In the commercial world, the key products that were driving the electronics industry were televisions, transistor radios and record players: these helped to maintain the health of the general industry, although many of the transistorised devices began to be imported from Japan, while American industry became dominant in semiconductors.

Transistor-based computers appeared in the mid-1960s but the most compact ones, by Digital Equipment Corporation, were American. A major British innovation around 1970 was the "Modular One" computer, designed by Ian Barron and using the fastest logic at the time, emitter-coupled logic (ECL) [13]. This, however, did not achieve great commercial success. A more orthodox British minicomputer, the GEC 4000, was more successful in the 1980s, but mainly in the UK, and was ultimately overtaken by workstation designs from the USA.

Also in the 1980s, the "home computer" began to become a significant market, starting with American imports, such as the Commodore PET and the Apple II, but then greatly undercut by cheaper British products, notably the Sinclair ZX80 [14] and the BBC Microcomputer [15]. These were still based on American microprocessors (MOS Technology/Rockwell 6502), but incorporated substantial innovation in their overall design, manufacture and software, such that this became a booming market for a while, only eventually undermined by the dominance of the IBM PC (although note that IBM had a significant manufacturing base in the UK). The BBC Microcomputer 
was actually designed and made by Acorn and this company evolved into the major processor design house ARM, which was taken over by a Japanese group relatively recently, although still headquartered in the UK.

The evolution of the business model of ARM is significant as it withdrew from hardware manufacture and oriented itself as an "IP (intellectual property) company", purely licensing the designs for complex microprocessors, the hardware for which would be made in silicon foundries in the USA or the Far East. Several other companies in Britain have also oriented themselves in this way. This illustrates the significant concentration of major silicon foundries in a small number of locations in the world, principally Taiwan, the USA, China and South Korea. This concentration in, essentially, two fairly small geographical regions is an interesting reflection of the effect of globalisation in this industry, but raises major questions of resilience of supply of this strategically significant commodity if conflict situations were to arise.

The entrepreneur behind the Modular One computer, Ian Barron, reappeared in the 1980s with a design for a radical type of microprocessor that was inherently optimised for parallel computer architectures, the "Transputer" [16]. A new company, Inmos, was set up in the UK to design and manufacture these devices and it achieved some success in parallel computers, especially those made by Meiko, also a British company. However, the parallel computer business has never been significantly profitable, mainly being driven by military needs, predominantly with United States Government finance, and Meiko eventually faded away in the 1990s.

It is noteworthy that Inmos was set up with funding from the UK government (controlled by the Labour Party at the time). It struggled to make profits and funding was withdrawn by the subsequent Thatcher (Conservative) government. This was probably the last time that the UK government attempted to subsidise innovative engineering.

The entrepreneur behind Sinclair computers, Clive Sinclair, had been a major figure in low-cost electronics, but his personal passion was always for electric vehicles. After the commercial failure of his Sinclair QL computer, he sold his computing interests to Alan Sugar (now just a reality TV star) and put all his efforts into small electric bicycles and tricycles, which were commercial failures [17].

At the end of the 20th century, a new start-up company, Cambridge Silicon Radio (CSR) was formed to design chips, principally for Bluetooth applications. In the nature of modern business evolution, the company frequently varied its product profile and acquired other companies. It became quite successful but eventually sold its Bluetooth activities to Samsung (Korea) and then the entire company was sold to Qualcomm (USA).

Finally, a small-scale initiative that is worthy of note is the "Raspberry $\mathrm{Pi}^{\mathrm{i}}$, which was designed and financed in Britain and is mass produced in a factory in South Wales. This was originally intended as an educational tool, to improve the understanding of computing in British schools. However, it has become a device with wider uses in small-scale control and other innovative applications of computers [18].

\section{Telecommunications}

Until the 1980s, civilian telecommunications in the UK was a government monopoly, run by the General Post Office. However, the hardware for it was provided by several, mostly British, private companies, notably Plessey and STC. Military telecommunications was oriented more towards wireless/mobile systems: Racal and Plessey dominated.

During the 1980s, the telecommunications component of the General Post Office was separated as 'British Telecom' (BT) and then the field was opened up to competitors. The mobile phone business grew beyond most expectations, with British expertise focused on network systems (e.g. Vodafone, which grew out of the military communications supplier Racal, illustrating the similarities between mobile and military technologies). Nokia also had a substantial manufacturing presence in the UK. In recent times, smartphone manufacture has been concentrated outside the UK, in Apple's suppliers and in the Far East, but Nokia and Siemens still have substantial manufacturing facilities for mobile network hardware in the UK. 
The advance of mobile communications has been as rapid in the UK as in many other areas of the world. First-generation has now been decommissioned and there are very few users of purely second-generation mobile. Third generation and fourth generation were both adopted at early stages and research into fifth generation is actively being pursued. $5 \mathrm{G}$ is expected to cause a significant shift in usage of mobile networks, away from dominance by handsets: there is likely to be a significant switch of static and nomadic Internet users from wired and WiFi connections to 5G but, more significantly still, it is expected that the 'Internet of Things' IoT will become a heavy user of 5G. However, there is at present no clear industry pathway for IoT device manufacture.

\section{Satellite Construction}

In developing its space industry, the British Government took a deliberate decision to avoid the glamorous aspects of launch vehicles and human spaceflight, instead concentrating on satellites, principally for telecommunications, this being seen as a more profitable business. This has been quite a successful strategy, although changes of globalised ownership have possibly caused some confusion. For some time, the satellite business was controlled by British Aerospace, but then there were various mergers and sales, such that it is now controlled by Airbus: this still retains large manufacturing facilities in the United Kingdom.

A very interesting independent British initiative has been Surrey Satellite Technology Limited, which was a spin-out from the University of Surrey. This has grown to be a major business, focusing on very small satellites for a range of purposes. Recently, the majority shareholding in the company has been sold to Airbus, but it retains its predominant base in the United Kingdom.

\section{Optical Fibre Communications}

Britain was a world leader in this field, with the discovery by Kao and Hockham (then principally associated with the British company Standard Telephones and Cables) that very long distance transmission in glass fibre was possible if impurities were removed [19]. It took some time for the materials science to produce the desired glass, but eventually it became a worldwide industry and Kao and Hockham won the 2009 Nobel Prize for Physics. Optical fibre (or fibre-optic) manufacture is now a healthy business in the UK, arguably dominated by the company Prysmian, which has evolved from the earlier BICC company (British Insulated Callenders Cables). Fibre-optic links are now commonplace for general telecommunications in the UK, although FTTP (fibre to the premises) is not widely available for domestic users. However, FTTC (fibre to the curb, or kerb in British English) is quite common, with the short link into the houses implemented in copper.

The increasing bandwidth that has become available requires very high performance transmit and receive modules and there was formerly a centre of excellence in this in Paignton, in south-west England. Unfortunately, globalised ownership has resulted in this being moved elsewhere in the world. Nonetheless, a new centre of expertise in the necessary compound semiconductors has developed in South Wales, in the company IQE Ltd (see below).

\section{The GEC Era}

The British General Electric Company (GEC - not connected with the American General Electric Company) was incorporated in 1889 and grew to be one of a few large general electrical companies in the UK. However, in 1961 it merged with a smaller radio and television manufacturing company and the son-in-law of the owner, Arnold Weinstock, became the managing director of the merged group. Weinstock then pursued an aggressive programme of acquisitions and profit maximisation that surprised many in the industry. In a major surprise, he took over two, larger, major electrical companies (AEI and English Electric), which included the British branches of Siemens and Marconi, and the Elliott computer company. Joint ventures with Siemens of Germany and Alsthom led to further expansion, including takeover of Plessey, Ferranti and the Vickers and Yarrow shipbuilding companies, which were strongly defence-oriented. 
The company made immense profits and was a dominant influence in the British economy but was arguably a retrograde influence on innovation. In 1996, Weinstock retired and the company disintegrated relatively rapidly. Defence aspects of the business were merged with British Aerospace to form BAE Systems. Much of the rest of the company was rebranded as Marconi and was then sold to Ericsson. Power aspects had previously been merged with Alsthom, which became fully French-owned as Alstom, but large parts of this were later sold (ironically) to American General Electric. GEC has thus effectively disappeared in the $21^{\text {st }}$ Century..

\section{Software}

It is in the nature of software that very small companies can produce very influential products: Microsoft is the outstanding example of this. There have been many small British software companies, but few have made a major impact on the international scene. One traditional one that might be mentioned is the Numerical Algorithms Group (NAG), which grew out of Nottingham University [20]. This continues to be a major supplier of mathematical algorithm software although this is not a particularly large business in financial terms.

Various innovators have tried to develop new programming languages and one interesting British example that can be quoted is occam, which was developed as an inherently parallel programming language for use with the Transputer [21]. Unfortunately, it was too idealistic, requiring a great deal of retraining for existing software users and hence it was not liked and was not widely adopted.

Computer games have been a relatively successful aspect of the British software industry, but the business environment is extremely turbulent, with companies appearing and disappearing at very short notice. A particularly successful one was Rockstar games [22], which produced "Grand Theft Auto": it is probably significant that this gave the appearance of being an American product and that may have helped its sales.

\section{Compound Semiconductors}

Although there are exceptions, most British efforts in silicon semiconductor devices have terminated as the industry is so heavily globalised that massive investment is required in advanced foundries. The winners in the global competition have tended to be in the Far East and the USA.

The situation with compound semiconductors is less clear-cut as they tend to be needed more for specialised markets such as radiofrequency, microwave and optics. A particularly successful British example is IQE Ltd, based in Cardiff, Wales, which has become a leader in compound semiconductors, with a particular emphasis on very high bandwidth active terminations for optical fibre links [23].

\section{The Future}

A major strand of current software activity is in cyber security, which is of importance to the overwhelming majority of activities in society. Much of the work is undertaken in secrecy and it is impossible to give a detailed overall picture. However, it can be noted that a leading research laboratory is the UK Government Communications Headquarters (GCHQ), in Cheltenham. A great deal of interest is now being directed towards the field of quantum computing, which has the potential to break existing encryption but also to create new encryption methods that should be unbreakable. This has been a theoretical concept for some time, but prototype quantum computers are beginning to be announced by some major companies and there has to be a strong suspicion that the intelligence community has already developed such a device.

When quantum computing becomes a commodity service, it is likely to cause a very radical transformation of the computing and communications industries although the actual manufacturers of the hardware are likely to follow the path of globalisation and hence it is to be expected that there will be a limited number of international players, as has been seen in the past with silicon devices. 
The general trend of British industry has been towards smaller productive units, whether actual SMEs (small to medium enterprises) or units belonging to larger conglomerates, and hence large and very visible factories concentrating on a single product have been in great decline. There are many such small units producing specialised electronic products and this situation is likely to continue into the future. One exception could be for electric and autonomous cars, where it is likely that the existing small number of car factories will transition towards manufacturing cars with a very large electronics content. However, it is likely that most of the electrical and electronic modules will be bought from specialist suppliers which will probably be part of globalised supply chains, such that some factories may be in the UK and some others elsewhere in the world.

\section{Conclusions}

Overall, the picture presented in the above review is not a particularly happy one, with many once-significant British companies having disappeared. This reflects the globalised nature of the industry, where software can be distributed around the world at almost zero cost and even the hardware tends to be so small that it can be shipped at very low cost. In addition, apart from semiconductor foundries, manufacturing facilities tend to be amenable to being set up with relatively low costs and hence they can also be moved around the world, depending on the availability of labour and finance.

Hence competition is global and the number of companies that win in the competition is very small. Even in the large American market one can observe companies flowering and then becoming small or disappearing. The dominant business model is that a small innovative company starts up and develops a product which briefly becomes very popular and then the company is taken over into a larger conglomerate. One partial exception in the British context is ARM Holdings, which is still based in Cambridge, but actually has multinational ownership nowadays.

Part of the strategy of governments in a small country like Britain is to attract branch divisions of major international companies and there has been some success in this in the past, notably with IBM and the former Digital Equipment Corporation, but these are no longer of great significance. Pragmatically, it can be said with some confidence that an attraction of Britain for international investors in the past was a combination of the English language and British membership of the European Union (EU). Unfortunately, the planned British withdrawal from the EU is likely to cause a major disruption to this business model. The hope is that British-owned companies will flourish instead, but this is speculative.

As an example of a large electrical and electronic conglomerate, the British General Electric Company (GEC) is a significant object lesson of a company which became very large and successful with extremely tight financial management, although this was at the expense of a rather low level of innovation. Eventually, this strategy failed, in a large part due to the problems of the dot-com bubble. Inasmuch as some other international companies have managed to maintain success with this model, notably Siemens and Hitachi, it can still be said to be a viable model, but it is difficult for a small country like Britain to rebuild strength in such an area once that strength has been lost.

Globalisation is a controversial topic politically, but since the 1980s the view of most political parties in the UK has been that manufacturing has to be governed by the market and that government subsidies are very unlikely to have successful outcomes. This means that a decline in income in the marketplace results in rapid closure or restructuring of manufacturing organisations, leading to a degree of instability and employment uncertainty. However, there seems to be no way of avoiding this and thus specialists working in the electrical and electronics fields need to keep themselves fully aware of innovations in technology and in cost reduction such that their companies, or at least their personal skills, remain relevant in the marketplace.

For the future, quantum computing must be seen as a major hope, given the probable depth of expertise that exists in the UK Government Communications Headquarters. Since this is a very secretive organisation, it is impossible to predict the path of development, but the amount of effort now being put into quantum computing internationally suggests that it will be a major transforming force in electronics and computing in the near future. More predictably, the Internet of Things will 
surely spawn utilisation of this technology in a wide range of industries. Some of these industries (e.g. the motor car industry) will probably develop in-house skills and hardware, but many other industries will prefer to buy from a specialist supplier: business patterns in this field are still nascent, but expectations of positive developments are high.

\section{Note}

This paper is an expanded version of a keynote presentation given at Moscow Institute of Electronics Technology in January 2018, as part of the 'ElConRus' conference for young Russian researchers.

\section{References}

[1] Dilhac, J.-M., 'Edouard Branly, the Coherer, and the Branly effect’, IEEE Communications Magazine, Vol. 47, 2009, pp. 20-26.

[2] Jensen, P.R., In Marconi’s Footsteps, 1894 to 1920: Early Radio’, Sydney: Kangaroo Press, 1994.

[3] Douglas, A., ‘The Crystal Detector’, IEEE Spectrum, Vol. 18, 1981, pp. 64 - 69.

[4] Eccles, W. H., 'John Ambrose Fleming. 1849-1945’. Obituary Notices of Fellows of the Royal Society. Vol. 5, 1945 , pp. $231-242$.

[5] Adams, M., 'Lee de Forest: King of Radio, Television, and Film’, New York: Springer, 2012.

[6] Clark, R.W., ‘Sir Edward Appleton’, Oxford: Pergamon, 1971.

[7] Constable, A., 'Early Wireless’, Tunbridge Wells: Midas Books, 1980.

[8] Appleton, E. V., Barnett, M. A. F. , ‘On some direct evidence for downward atmospheric reflection of electric rays’, Proc. Royal Soc. London, Part A, Vol. 109, 1925, pp. 621-641.

[9] Burns, R.W., ‘John Logie Baird: Television Pioneer’, London, IEE, 2000.

[10] Lovell, B., 'The Story of Jodrell Bank', Oxford University Press, 1968.

[11] Flowers, T.H., 'The Design of Colossus', Annals of the History of Computing, Vol. 5, 1983, pp. $239-252$.

[12] Sale, T., 'The colossus of Bletchley Park’, IEE Review, Vol. 41, 1995 pp. 55-59.

[13] Computer Technology Ltd., 'Modular One User Manual’, 1969. Available: http://www.computinghistory.org.uk/det/15946/Modular-One-User-Manual/

[14] 'ZX80', Available at: https://en.wikipedia.org/wiki/ZX80

[15] 'The BBC Microcomputer and me, 30 years down the line’, London: BBC. Available: http://www.bbc.co.uk/news/technology-15969065

[16] 'The Transputer’, Milton Keynes: National Museum of Computing. Available: http://www.tnmoc.org/special-projects/transputer

[17] 'Remembering the Other Inventions of Sir Clive Sinclair'. Available: https://www.digitiser2000.com/main-page/remembering-the-other-inventions-of-sir-clive-sinclair

[18] Raspberry Pi Foundation, 'Teach, Learn and Make with Raspberry Pi’, Available: https://www.raspberrypi.org/

[19] Kao, K.C. and Hockham, G.A., 'Dielectric-fibre surface waveguides for optical frequencies', Proc. IEE, Vol. 113, 1966, pp. 1151-1158.

[20] Numerical Algorithms Group, Oxford, UK. Available: https://www.nag.co.uk/

[21] Roscoe A.W.Hoare C.A.R.The laws of OCCAM programming', Theoretical Computer Science, Volume 60, Issue 2, September 1988, Pages 177-229

[22] Rockstar North, Edinburgh, UK. Available: http://www.rockstarnorth.com/

[23] IQE plc, Cardiff, UK. Avail: http://www.iqep.com/

(C) 2018 by the author(s). Published by Annals of Emerging Technologies in Computing (AETiC), under the terms and conditions of the Creative Commons Attribution (CC BY) license which can be accessed at http://creativecommons.org/licenses/by/4.0/. 